\title{
Constructional Meaning and Compositionality
}

\author{
Paul Kay
}

International Computer Science Institute and Department of Linguistics

University of California, Berkeley

\section{Laura A. Michaelis}

Department of Linguistics and Institute of Cognitive Science

University of Colorado Boulder

\section{Contents}

10 1. Constructions and compositionality

2. Continuum of idiomaticity

3. Kinds of constructional meanings

4. Model-theoretic and truth-conditional meaning

5. Argument structure

156 Metalinguistic constructions

7. Less commonly recognized illocutionary forces

8. Conventional implicature, or pragmatic presupposition

9. Information flow

10. Conclusion

\section{References}

Abstract

One of the major motivations for constructional approaches to grammar is that a given rule of syntactic formation can sometimes, in fact often, be associated with more than one semantic

25 specification. For example, a pair of expressions like purple plum and alleged thief call on different rules of semantic combination. The first involves something closely related to intersection of sets: a purple plum is a member of the set of purple things and a member of the set of plums. But an alleged thief is not a member of the intersection of the set of thieves and the set of alleged things. Indeed, that intersection is empty, since only a proposition

30 can be alleged and a thief, whether by deed or attribution, is never a proposition. This chapter describes the various ways meanings may be assembled in a construction-based grammar. 


\section{Constructions and compositionality}

35 It is sometimes supposed that constructional approaches are opposed to compositional semantics. This happens to be an incorrect supposition, but it is instructive to consider why it exists. A foundation of construction-based syntax is the idea that rules of syntactic combination (descriptions of local trees) are directly associated with interpretive and use conditions, in the form of semantic and pragmatic features that attach to the mother or

40 daughter nodes in these descriptions (Kay 2002; Sag forthcoming). This amounts to the claim that syntactic rules mean things. Meaning, of course, is generally viewed as the exclusive purview of words, and in the prevailing view of meaning composition, syntactic rules do no more than determine what symbol sequences function as units for syntactic purposes. So while syntactic rules assemble words and their dependent elements into

45 phrases, and the phrases denote complex concepts like predicates and propositions, the rules cannot add conceptual content to that contributed by the words; nor can they alter the combinatoric properties of the words. On this view, which Jackendoff (1997: 48) describes as the "doctrine of syntactically transparent composition", "[a]ll elements of content in the meaning of a sentence are found in the lexical conceptual structures [...] of the lexical items

50 composing the sentence" and "pragmatics plays no role in determining how [lexical conceptual structures] are combined". To embrace a construction-based model of semantic composition is not to reject the existence of syntactically transparent composition but instead to treat it, as per Jackendoff (1997: 49), as a "default in a wider array of options". That is, whenever a class of expressions can be viewed as licensed by a context-free phrase structure

55 rule accompanied by a rule composing the semantics of the mother from the semantics of the daughter, a construction-based approach would propose a construction that is functionally equivalent to such a rule-to-rule pair. But constructional approaches also provide a revealing way to represent linguistic structures in which semantics of the mother does not follow 
entirely from the semantics of the daughters. A case in point is the pattern exemplified by

60 the attested sentences in (1), retrieved from google. We will call such sentences pseudoconditionals, and we will refer to the if-clause and main clause as the pseudo-protasis and pseudo-apodosis, respectively.

(1) a. If you're 3Com right now, you're considering buying add space in next week's issue.

b. If you're George Bush, you're now allowed to lie in the faces of trusting young voters.

c. [I]f you're Betty Ford right now, you're probably thinking, you know, I hope everybody's OK.

d. More than one able program director thinks commercials, promos and features is not an all-news station,] but if you're new CBS President Dan Mason right now you're going to leave well enough alone.

Example (2) shows that the pseudo-apodosis, like a true apodosis, can be extended beyond the bounds of the initial sentence.

75 (2) If you are George W. Bush and this vending machine represents Iraq, you keep putting money into the machine. When you have none left and it is obvious to all rational persons that trying again is not going to result in a different outcome, you borrow more and keep going.

80 Syntactically the sentences in (1) and the first sentence in (2) appear to be ordinary conditional sentences like (3).

(3) If you're pleased with the outcome, you may feel like celebrating.

But the sincere speaker of the protasis of an ordinary conditional sentence does not

85 hypothesize a patently impossible state of affairs, while the if-clauses of (1)-(2) appear to pose the manifest impossibility that the addressee is identical to Peter Angelos/ Betty Ford/ George Bush/ Dan Mason/ etc. Of course that is not what is being said in (1)-(2). Exactly what is being said is difficult to pin down with certitude. The syntactic form is roughly given by (4).

90 (4) If you are $x, p(x)$. 
The semantics seems to assert the proposition expressed by $p(x)$, qualified in different examples by a number of different illocutionary forces or speaker attitudes. In any case, no hypothetical situation is posed; it appears that a categorical judgment is expressed (possibly

95 hedged or epistemically qualified in some way) and the subject of that judgment is not the addressee but the person identified as $x$; e.g., example (2) is clearly about George Bush, not about the consequences of a hypothetical identity between George Bush and the addressee. Pseudo-conditionals have the same form as (one type of) vanilla conditional but entirely distinct semantics.

100 If the grammar accords to a sentence a different interpretation from what could be built up piece by piece from its words and constituent phrases, syntactically transparent compositionality scores this as an instance of non-compositionality. As such, the pseudoconditional pattern could appropriately be called an idiom, but, as numerous proponents of construction-based approaches have observed, idiomaticity is not the same thing as

105 inflexibility (Fillmor, Kay \& O’Connor 1988, Michaelis \& Lambrecht 1996, Culicover 1999). The pseudo-conditional pattern is evidently a productive one, and an adequate grammar must describe the interpretive and combinatoric constraints that define it. In a construction-based grammar, the pseudo-conditional sits on a continuum of idiomaticity (or generality) of expressions, somewhere between tightly bound idioms and fully productive

110 processes. A construction grammar models this continuum with an array of constructions of correspondingly graded generality (Sag forthcoming). Doing so obviously requires many more rules of composition than are countenanced in most non-constructional approachesroughly as many as there are constructions listed in an (ideal) traditional grammar. A construction-based grammar sees nothing special about any part of the syntactic structure of 115 sentences like (1)-(2); the syntax of (1)-(2) is the same as the syntax of (3) - that of a 
common, garden-variety conditional sentence. But the meaning is different, and not obviously derivable by conversational implicature. So one posits a special construction with the syntax of a vanilla conditional, constrained as in (4), but with a semantic form unlike that of an ordinary conditional: a hedged categorical judgment is expressed—one whose subject

120 is not denoted in the pseudo-protasis.

The pseudo-conditional is important for our purposes because the existence of this interpretive affordance appearance to undermine one of the foundational assumptions of syntactically transparent composition, as expressed by the following quote (from the online Stanford Encyclopedia of Philosophy):

125 (5) "If a language is compositional, it cannot contain a pair of non-synonymous complex expressions with identical structure and pairwise synonymous constituents" (Szabó (2007)

If we use Szabó's diagnostic, the existence of pseudo-conditionals entails either that

130 English is not compositional or that pseudo-conditionals are syntactically distinct from ordinary present-tense conditionals. A view of compositionality this narrow also presumably necessitates different syntactic analyses for any pair of readings attached to sentences in the large class illustrated by (6)-(7). Each such sentence yields both an idiomatic and a composed interpretation:

135 (6) My yoga instructor sometimes pulls my leg. (7) I'm afraid he's going to spill the beans.

A constructional approach welcomes a single syntactic analysis in all of these cases and posits constructions in the case of the idiomatic readings that attach semantic interpretations

140 directly to certain relatively complex syntactic objects. In short, constructional approaches recognize as instances of compositionality cases in which two different meanings for the same syntactic form are licensed by two different collections of form-meaning licensers, i.e., by two different collections of constructions. Construction-based grammars are nevertheless 
compositional in a quite usual sense: if you know the meanings of the words and you know

145 all the rules that combine words and phrases into larger formal units, while simultaneously combining the meanings of the smaller units into the meanings of the larger ones, then you know the forms and meanings of all the larger units, including all the sentences. The 'bottom-up' procedural language used here is intended only heuristically: most constructional approaches are explicitly or implicitly declarative and constraint based,

150 notwithstanding the tempting metaphorical interpretation of construction as denoting the building of big things out of little things.

Constructional approaches tend to pay special attention to the fact that there are many such rules, and especially to the rules that assign meanings to complex structures. And such approaches do not draw a theoretical distinction between those rules thought to be of the

155 'core' and those considered 'peripheral'. Proponents of construction-based syntax assume that accounting for all the facts of a language as precisely as possible is a major goal, if not the major goal, of scientific linguistics. One can in fact view construction-based theories of syntax as upholding standards of grammar coverage that the original proponents of generative grammar abandoned, as they sought to reduce the theory's dependence on

160 linguistic facts. Chomsky (1995: 435) describes this shift in the goals of grammatical theory as follows: "A look at the earliest work from the mid-1950s will show that many phenomena that fell within the rich descriptive apparatus then postulated, often with accounts of no little interest and insight, lack any serious analysis within the much narrower theories motivated by the search for explanatory adequacy, and remain among the huge mass

165 of constructions for which no principled explanation exists - again, not an unusual concomitant of progress". It seems safe to say that most proponents of construction-based syntax would not consider the loss of insightful and interesting accounts a mark of progress, and find the search for putatively narrower theories of explanatory adequacy unrequited. 
Whether narrower properly describes a relation between the Minimalist Program, for

170 example, and, say, the construction-based version of Head Driven Phrase Structure Grammar of Ginzburg \& Sag (2000) is itself open to question. It can be plausibly argued that a formal theory, such as that of Ginzburg \& Sag, is ipso facto "narrower" than an informal one, such as the Minimalist Program, by virtue of the fact that formalism imposes a limit on potential predictions.

175 In the remainder of this article, we will examine how and what constructions mean. Section focuses on the continuum of idiomaticity alluded to above. Section 3 surveys the range of constructional meanings. Section 4 outlines the constructional approach to modeltheoretic and truth-conditional meaning. In section 5, we focus on argument-structure constructions of the kind proposed by Goldberg $(1995,2006)$. In section 6 , we describe the

180 relationship between constructional meaning and conventional implicature. Less commonly recognized illocutionary forces expressed by constructions are discussed in section 7 .

Section 8 discusses the relationship between constructions and metalinguistic operators, as discussed by Kay (1997), among others. In section 9 we will discuss constructional accounts of the discourse-syntax interface, with particular attention to the assignment of prosodic

185 peaks. Section 10 contains brief concluding remarks.

\section{Continuum of idiomaticity}

Related to the less restrictive view of compositionality is the recognition that there exists a gradient of idiomaticity-to-productivity stretching from frozen idioms, like the salt of the

190 earth, in the doghouse, and under the weather on the one hand to fully productive rules on the other, e.g., the rules licensing Kim blinked (the Subject-Predicate Construction) or ate oranges, ready to leave, and in the kitchen (the Head-Complement Construction). Several examples discussed below occupy intermediate points on this scale. 
At one end of the scale we find expressions like right away, as of [requiring a date or

195 time expression as complement], by and large, cheek by jowl, which are not only entirely fixed as regards their lexical makeup but also exhibit idiosyncratic syntax. Somewhat less idiosyncratic are expressions with fixed lexical makeup that exhibit syntax found elsewhere in the language, such as a red herring, carrying coals to Newcastle, and water under the bridge. Fillmore, Kay \& O’Connor (1988: 504) follow Makkai (1972) in pointing out that

200 many idiomatic expressions are no less idiomatic for being merely 'encoding' idioms. That is, someone who knows everything about the language except a particular encoding idiom may be able to decode that idiom on a first hearing, while still not knowing that the expression is a standard way of expressing that meaning. Examples of encoding idioms that are not decoding idioms are expressions like twist NP's arm, as for [when preceding a topic-

205 resuming NP], rock the boat or the French de vive voix ('orally in person', as against in writing; lit. 'of living voice'). In other words, idioms are defined not only as those expressions that are not interpretable by a naïve speaker but also as those expressions that a naïve speaker would not know to use in a given context. Close behind these come idioms that allow morphological inflection or minor syntactic alteration such as

$210 \mathrm{kick} / \mathrm{kicks} /$ kicked/kicking the bucket. More productive than these are idioms with partially fixed lexical membership. Examples include the [Watch NP[ACC] VP[bse]] pattern that occurs in a sentence like "I've taught you well, now watch you/*yourself beat me." Many subtypes of idioms fit in this category: among others, VP idioms with fixed verb and controlled or uncontrolled pronominal argument (8), VP idioms with variable object (9), the

215 rare subject idioms (10). Note in the case of (10c) that the idiom (construction) specifies interrogative form but does not specify main-clause syntax versus that of embedded question.

(8) a. blow one's nose

b. blow someone's mind 
a. slip someone a Mickey

b. give someone the slip

(10) a. The world has passed someone by.

b. Someone's time is up.

225

c. Where does someone get off?/I wonder where someone gets off.

Nunberg, Sag \& Wasow (1994) demonstrate that VP idioms behave in ways that are explicable if they have compositional properties - that is, if their parts map in a one-to-one way to the parts of their paraphrases. In particular, they argue, the rarity of subject idioms, exemplified in (10), follows from the fact that the arguments of verb-headed idioms, even

230 when lexically animate, denote inanimate entities, as evidenced by the second arguments of the expressions let the cat out of the bag, throw the baby out with the bath water, take the bull by the horns. Since subject arguments tend to be interpreted as agents, and therefore as animates, it stands to reason that so few idiomatic expressions constrain the subject role. In addition, they argue, differences in the degree of syntactic flexibility exhibited by VP idioms

235 can be attributed to differing degrees of (sometimes metaphorically based) semantic compositionality, where flexibility includes the availability of a passive paraphrase (e.g., The beans were spilled, as against * The bucket was kicked) and the felicity of nominal modification, as in the attested example Clinton and McCain both have much larger, more repugnant skeletons in their closet (retrieved from google), as against, e.g., *He blew some

240 ludicrous smoke. Crucially, the type of semantic transparency that Nunberg, Sag \& Wasow see as driving syntactic flexibility cannot be equated with the existence of a general semantic motivation for the VP idiom, e.g., one involving metaphor or metonymy. For example, the expression chew the fat describes the jaw motions associated with talking, while the expression drop the ball presumably evokes the metaphor LIFE IS A GAME. Neither

245 expression, however, maps in a one-to-one fashion to its literal paraphrase (which we presume to be 'converse' and 'fail', respectively). Accordingly, neither expression exhibits syntactic flexibility: *The fat was chewed, *He dropped the important ball. Because 
semantically transparent VP idioms must combine with constructions like passive and modification, they require a compositional representation, as verbs with partially lexically

250 filled valence lists.

An example of an idiom, or construction, which is both defined largely syntactically and also contains a significant amount of specified lexical material is Nominal Extraposition, an exclamatory construction studied by Michaelis \& Lambrecht (1996) and exemplified by attested cases in (11):

255 (11) a. It's amazing the people you see here. (Michaelis \& Lambrecht 1996: 215, (1a))

b. It was terrible, really, the joy I took at the notion of skunking Pigeyes. (Michaelis \& Lambrecht 1996: 215, (1e))

c. It's staggering the number of books that can pile up. (Michaelis \& Lambrecht 1996: 215, (1g))

The syntax of the construction is roughly as summarized in (12):

(12) It BE $\mathrm{AP}[\mathrm{NP}$ the $\mathrm{CN}]$.

265 Michaelis \& Lambrecht argue that Nominal Extraposition, in contrast to the superficially similar pattern right-dislocation pattern, has a nonreferential subject (invariantly $i t$ ) and a focal rather than topical post-predicate NP. The pattern qualifies as an idiomatic pattern on the basis of its syntax (adjectives do not otherwise license non-oblique complements), its semantics: the post-predicate NP is metonymically construed as referring to a scalar

270 parameter, e.g., the number or variety of people seen in (11a).

Moving onward toward purely formal idioms, we encounter the much discussed Correlative Conditional (or, equivalently, Comparative Correlative), exemplified in (13):

(13) The more I drink the better you look.

275 The only lexically specified elements in the Correlative Conditional are the two tokens of the, which only coincidentally have the form of the definite article: these forms are in fact reflexes of Old English instrumental-case demonstratives (Michaelis 1994a). With the 
exception of idiomatic comparative expressions like the better to see you with and all the more reason to, the word the serves as a degree marker only in the Correlative Conditional 280 (Borsley 2004, Culicover \& Jackendoff 1999, Fillmore, Kay \& O’Connor 1988, Fillmore 1986). Finally, when no lexical material is encountered in an idiom, we have entered the realm of minor syntactic patterns. Well-known examples include the Incredulity Construction (Akmajian 1984, Lambrecht 1990), as exemplified in (14), and the conjunctional conditional. The latter construction, exemplified in (15), expresses a range of

285 comissive speech acts (Culicover 1970 and Cornulier 1986):

(14) Him get first prize?!

(15) a. One more beer and I'm leaving.

b. Bouges pas ou je tire! ('Don't move or I'll shoot!')

290 The step from these relatively special-purpose syntactic patterns to those that license canonical statements, imperatives, questions of many different types (Ginzburg \& Sag 2000), ordinary noun phrases, head complement phrases, etc. is a small one. A close look at the variety of constructions in English - and presumably in many, if not all, other languages - reveals, not a dichotomy between core and peripheral constructions, but a

295 gradient of fully fixed to fully productive patterns of phrase construction. The semantics of constructions is the semantics to be discovered along the full length of this gamut.

3. Kinds of constructional meanings

Probably any kind of meaning that occurs can be the semantic contribution of a construction. The classification implied in the following list is intended to be neither definitive nor 300 exhaustive.

(i) Literal meaning in general, especially that concerned with the truth conditions of statements and the straightforward interpretations of questions and imperatives: the kind of meaning that formal semantics has traditionally been primarily concerned with. 
(ii) Argument structure in particular.

(iii) Conventional implicatures, or pragmatic presuppositions.

(iv) Less commonly recognized illocutionary forces, as in the incredulity construction (14) or the construction that announces an observed incongruity and requests an explanation for it (as in, e.g., What are you doing smoking?)

(v) Metalinguistic comments, as in metalinguistic negation (e.g., It's not good, it's great!) or the metalinguistic comparative (e.g., He's more annoying than dangerous.)

4. Model-theoretic and truth-conditional meaning

315 Normally, a construction specifies a syntactic configuration, usually (in some constructional approaches, always) a local tree, consisting of a mother node and one or more daughter nodes. Sag's Sign-Based Construction Grammar (Sag forthcoming) distinguishes between lexical constructions, which describe lexeme classes, and combinatoric constructions, which describe phrasal types. (For recent precursors to this approach, see the constructional HPSG

320 of Ginzburg \& Sag 2000, and the constructional approaches of Kay \& Fillmore 1999, Kay 2002, 2005, Michaelis \& Lambrecht 1996 and Michaelis 2004.) The construction also specifies how the semantics of the daughters are combined to produce to semantics of the mother, and what additional semantics, if any, is contributed by the construction itself. Current Sign-Based Construction Grammar (Sag forthcoming) uses a modified form of

325 Minimal Recursion Semantics (Copestake et al. 2005), but constructional approaches in general are not constrained to any particular semantic theory, formal or informal. A fully developed formal analysis of the semantics and syntax of a very wide range of English interrogative clauses is given in Ginzburg \& Sag 2000. That work represents perhaps the most extended formal fragment of any grammar that deals in full detail with both the 
330 syntactic and semantic phenomena of a large domain, as well as the exact specifics of their interrelations. As such it presents arguably the fullest available concrete demonstration of the principle of compositionality. Ginzburg \& Sag implement the notion of construction in the formal device of typed feature structures (briefly 'types') organized as a multiple inheritance hierarchy. This enables them to build a hierarchy of types, with initially separate

335 syntactic and semantic branches, which however are mixed and matched by virtue of multiple inheritance into hybrid syntactico-semantic types that pair structure and meaning. These hybrid types are intended as fully explicit implementations of the traditional notion of a construction as a conventional (specifically, grammatical) association of form and meaning. This $400+$ page, tightly written treatise contains too much material to be

340 summarized here, but some idea of the coverage - if not the novel semantic theory of interrogatives - can be given by the leaves (maximal subtypes) of the hierarchy of interrogative clauses, which present fully explicit constructions specifying the syntax and semantic of the six major types of interrogative clauses given in (16), plus the thirteen subtypes suggested by multiple examples.

345 (16) a. polar interrogative clause: Did Kim leave?

b. non-subject wh interrogative clause: What did Kim see? [I wonder] what Kim saw

c. subject wh interrogative clause: Who left? [I wonder] who left

d. reprise [i.e., echo] interrogative clause: You saw WHO? Did I see WHO? Go WHERE? You're leaving?

e. direct in-situ interrogative clause: You saw WHO? Kim saw Sandy?

f. $\quad$ sluiced interrogative clause: Who? I wonder who.

Ginzburg \& Sag (2000) present separate constructions specifying the full syntax and

355 semantics of each of these thirteen interrogative-clause types, as well as the complex interrelations of the various syntactic and semantic types they inherit. Sag (forthcoming) generalizes the Ginzburg \& Sag analysis by analyzing the interrogative patterns in (16) as subtypes of the head-filler construction, along with other constructions that license longdistance dependencies, including topicalization, $w h$-exclamatives, relative clauses and the 
360 clauses of the biclausal correlative conditional discussed in section 2 above. Sag observes that while each of these clause types exhibits an extraction dependency between a clauseinitial filler phrase and a gap in the clausal head daughter, there are several parameters of variation that distinguish these types from one another, including: the type of the filler (i.e., whether it contains a $w h$-element and, if so, of what kind), the possible syntactic categories

365 of the filler daughter, the semantics and/or syntactic category of the mother and the semantics and/or syntactic category of the head daughter. He shows that each of the five subtypes of the filler-gap construction imposes a distinct condition: the filler daughter of a topicalized clause must contain no distinguished element (wh-phrase or the-phrase), whinterrogative, $w h$-relative, and $w h$-exclamative clauses each require the filler daughter to

370 contain a distinct type of $w h$-element and the filler of a the-clause must contain the definite degree marker the. Paralleling these syntactic differences are semantic and discoursepragmatic differences; for example, while interrogative clauses denote propositional functions, exclamatory clauses like What a nice person Sandy is denote 'facts' (presupposed propositions). Because the type descriptions that define constructions in this system can

375 involve any combination of syntactic, semantic and use conditions, the model can incorporate types that have even more specific formal, interpretive and pragmatic constraints than those just discussed. These types include the interrogative construction illustrated in (17), which Fillmore \& Kay (1999) refer to as the WXDY construction:
a. What's this fly doing in my soup?
b. What's this scratch doing on the table?
c. Can you tell me what this scratch is doing on my favorite table?

What makes the construction undeniably idiomatic is that it is a why question that takes the form of a what question. At the same time, as Kay \& Fillmore (1999) demonstrate, the 385 pattern partakes of many semantic regularities. First, the predication expressed by $\mathrm{Y}$ is applied to $\mathrm{x}$ in the standard way that any (one-place) predicate is applied to its argument, 
resulting in the proposition $\|\mathrm{Y}(\mathrm{x})\|$; it is this proposition, e.g., 'There's a fly in my soup', that is subject to the special, explanation-seeking illocutionary force. Second, within the $\mathrm{Y}$ constituent, the semantics is assembled according to the familiar rules for assembling the

390 semantics of prepositional phrases (17), adjective phrases (18a), gerundial clauses (18b), predicational noun phrases (18c):

(18) a. What are you doing stark naked?

b. What was he doing running for office?

c. What's she doing only the runner up?

395

So sentences exemplifying the WXDY construction seamlessly interweave the semantic structures of the familiar constructions involved, e.g., those that license the Y predicate, nonsubject wh interrogatives (main clause with inverted head daughter or embedded and canonical), with a special illocutionary force to compose their meaning. Constructional

400 approaches recognize the responsibility to account in a compositional way for the meanings of wholes in terms of the meanings of their parts and the rules of combination, that is, the constructions.

\section{Argument structure}

405 The principal contribution of constructional approaches to the semantics of argument structure has been the thesis that patterns of argument structure (argument structure constructions) exist independently of lexical argument-taking predicates. Adele Goldberg has been the leading exponent of this view (see, e.g., Goldberg 1995, 2006, Kay 2005 and Michaelis 2004). Among the argument-structure constructions proposed by Goldberg are

410 the Caused Motion Construction, the Way Construction and the Ditransitive Construction ${ }^{2}$. The Caused Motion Construction is motivated by examples like (19)-(22): 
(19) a. They laughed him off the stage.

b. *They laughed him.

(20) a. Frank sneezed the tissue off the table.

b. *Frank sneezed the tissue.

(21) a. She let the water out of the tub.

b. $\quad *$ She let.

(22) a. Frank squeezed the ball through the crack.

b. Frank squeezed the ball.

425 In (19)-(20) the verb can be used intransitively (not illustrated above) but cannot be used transitively without the path expression (as shown in the b versions). In (21) the verb also cannot be used transitively without the path expression and cannot be used intransitively either. In (22) the verb can be used intransitively but does not have a motion-causing meaning when so employed. Clearly, the verb itself does not license the path PPs in (19)-

430 (22), so something else must. Goldberg posits a Caused Motion Construction, an independent argument-structure construction (ASC), as the licenser. This construction adds the notion of caused motion to the semantics of the verb and the preposition. Gawron (1985, 1986) and others had argued that pragmatic inference is sufficient to complete the picture in the interpretation of, e.g., (20) by adding to the explicitly expressed propositions that (1)

435 Frank sneezed and (2) the tissue found itself off the table and (3) the pragmatic inference that Frank's sneezing must have caused the tissue to find itself off the table.

Goldberg's counterarguments include the observation that many languages do not permit this kind of construction, owing to the prohibition against the manner and fact-of-motion

${ }^{2}$ Kay (2005) prefers the term "Recipient Construction" because his analysis provides a construction for the 'dative moved' property of a verbal valence sufficiently abstract to operate with both active and passive moods. 
440 event components in verb-framed languages (Goldberg 1995: 155, citing Talmy 1985) and the observation that some of the criticism is based on the confusion of merely decoding idioms with true encoding idioms - the latter requiring representation in the grammar because they are not deducible from anything else in the grammar. Kay (2005) acknowledges Goldberg's main point: that something has to be added to the grammar to

445 license the path expressions, but suggests that both agentive transitivizing constructions and path adjunct constructions are independently required to derive (23b) and (23c), respectively, from (23a). He argues that if an independent Caused Motion Construction is posited, the analysis attributes to (23d) a spurious ambiguity.

450 (23) a. The top was spinning.

b. Kim was spinning the top.

c. The top was spinning off the table.

d. Kim was spinning the top off the table.

455 Kay also argues that the proposed Caused Motion Construction overgenerates, presenting examples like those in (24):

(24) a. *He bragged her to sleep.(Cf. He bored her to sleep)

b. *The storm raged the roof off the house. (cf. The storm tore the roof off the house.)

460 While this argument provides an alternative analysis for examples like (22), it does not provide an account for examples like (20)-(22), in which there is no independent active transitive version of the verb. ${ }^{3}$

${ }^{3}$ The argument against the Caused Motion Construction becomes somewhat fractionated at this point, taking various views on the troublesome examples. Example (19) can be seen as semi-lexicalized; compare (i)

(i) ??They snored him off the stage.

According to this argument, (19) participates in a pattern of coinage that is not productive synchronically, like the pattern exemplified by the metaphorical comparatives heavy as lead, light as a feather, old as the hills/Methuselah, happy as a lark and easy as pie. But there are 
The Way construction, exemplified in (25) provides a straightforward (although not

465 necessarily simply analyzed) example of an ASC (Goldberg 1995: 202ff, Levin and

Rapoport 1988, Jackendoff 1990):

(25) a. She was hacking her way through the brush, when...

b. He whistled his way home.

c. *He whistled her way home.

470

The construction requires an intransitive verb (or a transitive verb used intransitively, such as eat or drink) and adds to its valence a NP that occurs in what is normally object position — but which does not passivize to subject — and an additional phrase of any syntactic category denoting a path or destination. The pseudo-object NP is determined by a

475 possessive pronoun that is co-construed with the subject. One is inclined to dub this NP a pseudo-object because it cannot co-occur with an object, as illustrated in (26):

(26) a. She entertained her way into café society.

b. $\quad$ *She gave parties her way into café society.

In all cases the path or destination predicate is interpreted as predicated of the denotatum of the subject. Hence the denotatum of the subject is understood as moving either to a destination or along a path (or both). Thus in (25a) 'she' was traveling through the brush

those who argue that such patterns of coinage, although not productive synchronically, should nevertheless be considered constructions of the language and included in the grammar. The argument against the Caused Motion Construction holds that tokens like (1923) are analogical, nonce creations, not licensed by the grammar. Again, there does not seem to exist convincing evidence either for or against the nonce-creation view. Examples of this kind occur relatively rarely (an observation that supports the nonce-creation view) but with a relatively wide variety of verbs (an observation that undermines it); they sound strained or poetic to proponents of the nonce-creation view but (apparently) less so to advocates of the Caused Motion Construction. Whether or not it is decided that English contains a Caused Motion Construction, Goldberg's larger claim that caused-motion phenomena motivate the existence of ASCs, which expand the semantic and syntactic valences of verbs, appears sound. 
and in (25b) 'he' got home. In examples like (25a) the type of eventuality denoted by the

485 verb is interpreted as providing a means that enables the movement (along the path or to the destination), overcoming some presupposed obstacle or other difficulty. The presumption of difficulty explains the sort of contrast exemplified in (27), according to which ordinary verbs of locomotion require a special context that provides an image of difficulty to sound acceptable in such sentences.

490

(27) a. ??She walked her way home.

b. ??She swam her way across the pool.

c. Exhausted by the struggle, she barely managed to swim her way to safety.

495 In examples like (25b), the type of eventuality denoted by the verb is interpreted as an accompaniment or a manner of the movement. Goldberg (1995: $210 \mathrm{ff}$.) sees the availability of both means and manner readings as evidence of constructional polysemy, pointing to precedents in the lexicon.

500 (28) a. Bob cut the bread with a knife. (means) [Goldberg 1995: 211, (37)]

b. Bob cut the bread with care. manner) [Goldberg 1995: 211, (38)]

(29) a. Pat found a way to solve the problem. (means) [Goldberg 1995: 211, (40)]

b. He had a pleasant way about him. (manner) [Goldberg 1995: 211,(41)]

505

More formal, constraint based approaches, such as SBCG, would analyze the relations between examples like (25a) and (25b) as illustrating inheritance of identical syntax and largely overlapping semantics by two distinct constructions, leaving discussion of the extension of means to manner semantics as belonging to the history of the language rather

510 than the synchronic grammar.

Most constructional approaches to argument structure have considered either additions to 
the argument structure of verbs or alternate syntactic valences with possible semantic consequences as in the dative alternation. Goldberg (1995: 141-151) and Kay (2005: 71-98)

515 have provided analyses of the 'Dative Movement' alternation in somewhat differing constructional frameworks, Goldberg's relying on the notion of constructional polysemy, radial categories of ASCs, and various types of links among senses of a construction. This approach is close in spirit to much of the work in cognitive linguistics. Kay's approach is more similar to SBCG and the more formal constraint-based approaches to grammar. Both

520 approaches agree that one or more argument-structure constructions are necessary to provide the special syntax of sentences like (30):

(30) Kim sent Sandy a letter.

525 and to account for the well known contrast of acceptability illustrated in (31).

(31) a. Kim forwarded the letter to Sandy.

b. Kim forwarded Sandy the letter.

c. Kim forwarded the letter to Oshkosh General Delivery.

d. *Kim forwarded Oshkosh General Delivery the letter.

Whereas the destination of the transfer in (31a) and (31c) is not constrained to be a recipient, it is so constrained in (31b) and (31d). Before leaving the topic of argument structure constructions, we should note that ASCs do not always add arguments or shuffle them

535 around arguments furnished by the lexical predicator. ASCs may also delete arguments, as is the case of certain French reflexives, which inchoativize inherent transitives. Some French reflexives are presumably derived from transitive counterparts by removing an agentive subject valent both semantically and syntactically, rather than indicating that the subject's denotatum is performing a reflexive action. For example démocratiser is necessarily 540 transitive and means 'to make [something] democratic'; similarly ameliorer is necessarily 
transitive and means to 'improve [something]', but the reflexive versions se démocratiser and s'ameliorer do not mean 'to democratize itself/oneself' or 'to improve itself/oneself', but merely 'to become democratic' and 'to improve'.

545 6. Conventional implicature, or pragmatic presupposition

One of the areas in which constructional approaches have contributed to semantics is that of conventional implicature or pragmatic presupposition. It seems appropriate to allow the notion of compositionality to comprise these 'pragmatic' instructions embedded in the grammar that provide the addressee with a certain semantic structure and instruct him or her

550 to find content in the context that satisfies that structure. Consider utterance of a sentence like (32):

(32) Kim won't (even) get question eight right let alone Sandy get question nine.

Sentence (32) asserts that Kim and Sandy won't get the correct answers to questions eight and nine, respectively. But there is rich content to (32) beyond these truth conditions (Fillmore, Kay \& O'Connor 1988). The use of let alone to connect the two clauses signals that the first unilaterally entails the second, and thus suggests the paraphrase in (33).

(33) Kim won't get problem eight right; a fortiori Sandy won't get problem nine right.

And this entailment takes a particular form. In this example, we have to think that the problems can be arranged on a scale (presumably of difficulty) and students arranged on a

565 scale (presumably of ability) where the scales are interrelated in such a way that a more able student will answer correctly any problem that a less able one will and a less able student will miss any problem that a more able one misses. A network of propositions connected by 
entailments of this kind has been called a scalar model (Kay 2004: 684). Scalar models have several interesting general properties. Two of these properties are that the form of a scalar

570 model can be made mathematically precise (for the formal details, see Kay 1990), and that its content is left entirely open to retrieval from context, including background knowledge (Fillmore, Kay \& O’Connor 1988, Kay 1997). The latter property is perhaps more readily appreciated with an example like (34).

575 (34) SANDY doesn't eat CHICKEN let alone KIM eat DUCK.

An utterance of (34) could be readily interpreted in a context in which duck is viewed as more expensive than chicken and Kim as more frugal than Sandy—or in a context in which 580 duck is viewed as meatier than chicken and Kim is viewed as a stricter vegetarian than Sandy — or in a context in which duck is viewed as more exotic than chicken and Kim as more squeamish than Sandy. The let alone operator instructs the addressee to find in the context a scalar model that is induced by two unidimensional scales, here of eaters $<\mathrm{x}_{1}, \mathrm{x}_{2}, \ldots$ $\mathrm{x}_{\mathrm{n}}>$ and foods $\left\langle\mathrm{y}_{1}, \mathrm{y}_{2}, \ldots, \mathrm{y}_{\mathrm{m}}\right\rangle$, and a propositional function (here: $\mathrm{x}_{\mathrm{i}}$ doesn't eat $\mathrm{y}_{\mathrm{j}}$ ), such that 585 whatever Kim will eat Sandy will eat and whoever doesn't eat chicken necessarily doesn't eat duck. In the let alone construction the content of the scalar model is left for the addressee to extract from the context although the form of the model is strictly fixed. It is this property of directing the addressee to extract information of a prescribed form from the context that motivates the appellation 'contextual operator'.

590 An additional component of the meaning of the let alone is discussed further in section 9: the negation of the proposition denoted by the second clause is taken to be in the context. For example, a successful utterance of (34) requires a conversational context in which the 
proposition that Kim will eat duck is on the floor (though not necessarily taken for granted ${ }^{4}$ ). The construction seems designed for use in a circumstance in which the demands of Gricean

595 Quantity conflict with those of Relevance (Relation). For example, an utterance of (34) would be most appropriate in a context where the proposition that Sandy eats chicken has been asserted or questioned, and the speaker feels that rather than respond directly with a denial it would be more informative to reply that Kim does not eat duck, since the latter entails the correct answer to the former and provides additional, presumably relevant,

600 information.

Contextual operators can be parasitic upon one another, by which we mean that when two occur in the same utterance the conceptual output of one can serve as input to the other. Consider respective and vice versa. First we establish that each of these expressions is a contextual operator. Respective (and respectively in a somewhat different fashion)

605 presuppose a mapping relating two sets ${ }^{5}$, but in effect instruct the addressee to discover in the context the rule establishing the mapping (Kay 1989). Consider a sentence like (35):

(35) The teachers called their respective mothers.

610 An utterance of this sentence could of course be used in a context where the teachers' mothers were the intended receivers of calls but it could also be used in a context of a parent-

${ }^{4}$ For instance, the context proposition might have been introduced in a question: I wonder if Kim eats duck?

${ }^{5}$ Usually the mapping is bijective - perhaps for some speakers, always so. For speakers accepting sentences like (i), the mapping can be many-one, and for those accepting sentences like (ii), it can be one-many:

(i) ?Each of the 100 dolls was assigned to one of ten trunks and every doll was packed into its respective trunk.

(ii) ?Each salesman was assigned ten clients to call and every salesman called his respective clients. 
teacher association function where each teacher has been assigned one (or more) mother to call. Figuring out from context the mapping relation that yields the codomain is the responsibility of the addressee.

615 Interpreting a sentence containing vice versa can likewise be shown to depend crucially on the addressee's finding needed information in the context. This can be seen by first considering a sentence that presents an ambiguity that can only be resolved by context. In (36) only context can decide the ambiguity between the referential (John) and bound variable (Every boy) reading of the pronoun.

620

(36) $\mathrm{John}_{\mathrm{i}}$ thinks [every boy $]_{\mathrm{i}}$ loves his $\mathrm{i}_{\mathrm{i}, \mathrm{j}}$ mother.

If we embed a sentence with this kind of ambiguity under the vice versa contextual operator, we see that the ambiguity is maintained.

625

(37) John thinks that every boy loves his mother and vice versa.

Sentence (37) will convey John's conviction of mutual love between himself and every boy's mother only if the referential interpretation is dictated by the context in which the

630 sentence is heard. By the same token, only if the context dictates the bound variable interpretation, will the sentence convey John's conviction that all mother-son pairs are mutually loving. An ambiguity comparable to but distinct from that created by the referential versus bound variable reading of the pronouns in (36) can be created by respective.

635 (38) The secretaries called their respective senators.

In (38), the relation pairing secretaries and senators must be recovered from context. The senators may be the employers of the secretaries, pen pals, and so on. If we put both contextual operators into the same sentence, as in (39), the one with wider scope will take

640 the conceptual output of the one with narrower scope as its input. 
The secretaries called their respective senators and vice versa.

Whatever relation is contextually recovered as pairing secretaries $<\mathrm{x}_{1}, \mathrm{x}_{2}, \ldots \mathrm{x}_{\mathrm{n}}>$ with

645 senators $<\mathrm{y}_{1}, \mathrm{y}_{2}, \ldots, \mathrm{y}_{\mathrm{n}}>$ will establish the relation $\{<\mathrm{x}, \mathrm{y}>\mid \mathrm{x}$ called $\mathrm{y}\}$ as the meaning that is fed into the vice versa operator, which in turn will yield the meaning $\{<\mathrm{x}, \mathrm{y}\rangle \mid \mathrm{x}$ called $\mathrm{y} \& \mathrm{y}$ called $\mathrm{x}$. . (For further discussion of these and other examples of contextual operators, see Kay 1997, Michaelis 1994b on Vietnamese markers of expectation violation and Michaelis 1996 on the aspectual adverb already.)

650

A view closely related to that of contextual operator is that of Fillmorean frames, which provide an alternative explanation for many of the phenomena that go under the heading of presupposition in the formal semantic literature. Gawron (this volume) discusses Fillmore's well-known example of on the ground versus on land (Fillmore 1985). An utterance

655 employing the former expression is likely to presuppose a context including an air voyage while the latter is likely to presuppose a sea voyage. The striking aspect of the example is these expressions appear to denoted the same thing and differ only in the background frame they rely on and therefore evoke when uttered. Somewhat similarly, Fillmore has discussed at length the "commercial-event frame", which seems to provide background for and be

660 evoked by a rather long list of words, including buy, sell, cost, price, goods, etc. Frame semantics provides a persuasive semantic theory at the lexical level; the mechanism that combines the meanings of words and elementary constructions into the meanings of sentences has received less attention in this tradition. (For further discussion see Gawron (this volume) and the Fillmore references cited therein.)

665

7. Less commonly recognized illocutionary forces 
A number of constructions appearing in recent constructionist writings have involved special illocutionary forces, beyond the familiar ones of imperatives, questions, and a handful of others. Perhaps the most familiar such special illocutionary force is that associated with the

670 "Mad Magazine" sentence type (Akmajian 1984, Lambrecht 1990); it is illustrated by (14), repeated below:

(14) Him get first prize?!

The force of this sort of sentence appears to be an expression of incredulity, but perhaps a

675 particular nuance of that attitude expressible only in this or a small number of other forms.

Somewhat similarly perhaps, it is difficult to gloss the force of the construction illustrated in (7), repeated below:

680

(7) Watch me get wet.

The particular attitude conveyed by using this form has been described as "conjuring fate", but capturing the exact signification of this sentence form is not easy. Again, it is possible that this particular illocutionary meaning is expressible only in this form.

Another special illocutionary force displayed by a construction discussed above that of 685 examples $(17 \mathrm{a}, \mathrm{b})$ repeated.

(17) a. What's this fly doing in my soup?

b. What's this scratch doing on the table?

The illocutionary force conveyed by this construction seems roughly to be that of pointing 690 out an anomaly and expressing a desire for an explanation of it.

The special force or forces of the pseudo-conditional construction, exemplified in (1-2) above and in (40) below, seem especially hard to pin down. The examples in (40) present the first five relevant Google hits that matched the pattern "If you're $\mathrm{x}$ * you...". After viewing quite a few attested examples we confess to failure in isolating what the choice of 
695 the pseudo-conditional construction adds to or subtracts from a simple assertion of the proposition (or posing the question or imperative) formed from the pseudo-apodosis by substituting the person the (pseudo-) addressee is identified with in the pseudo-protasis substituted for "you". We leave figuring out the illocutionary function of this construction as an entertainment for the reader.

700

(40) a. We make a living by what we get, Churchill said, but we make a life by what we give. And to save a life? If you're Bill Gates, the richest man in the world, you give fantastic sums of money [...]. If you're a rock star like Bono, you give money. [...] If you're Bill Clinton and George H.W. Bush, you raise money - but you also give the symbols of power and the power of symbols[...].

b. Look, Davis is the boss and can sign and cut whoever he wants. It's just that communication is not one of his strengths. If you're the coach of the Raiders, you deal with it.

c. [I]f you're Britney Spears' publicist you might as well go ahead and kill yourself. Unless you have a time machine, there's no way to fix this.

d. The Firearms Waiting Period : No, that's not the waiting period to buy a gun. If you're Dick Cheney, that's the time you take until you get around to reporting you've shot somebody.

e. If You're Barack Obama, How Much Do You Trust Howard Dean?

The illocutionary force of the pseudo-conditional resembles that of speech-act conditionals, as described by Sweester (1994). In a speech-act conditional, the antecedent clause describes a hearer-based preparatory condition on the commissive act expressed

720 (indirectly) by the consequent clause. For example, the speech-act conditional If you need anything, my name's Terry expresses in its consequent clause an indirect offer of assistance - acceptance of which will require hailing the speaker - and in its antecedent clause a preparatory condition upon that act: the hearer must have a need for assistance. Similarly, the pseudo-conditional antecedent describes the conditions under which the

725 second-person reference in the consequent clause is felicitous - namely, that the hearer has agreed to engage in a theory-of-mind exercise in which he or she will simulate the consciousness of the person named in the antecedent clause. 
8. Metalinguistic constructions

730 Horn's (1985) analysis of metalinguistic negation (see also Horn 1989: Chapter 6). ${ }^{6}$ Horn showed that a sentence like (40) could not be analyzed by positing either a very general kind of propositional negation or two separate propositional negation operators in English (or languages with a similar phenomenon), primarily based on examples like those in (41).

(40) The King of France is not bald, because there is no King of France.

735

(41) a. Her name isn't [æn'drijə]; it's [andrej'ə].

b. It's not pretty; it's gorgeous.

c. It's not the unique criteria; its the unique criterion.

d. The cow isn't pissing, son, she's urinating.

740

None of the examples in (41) expresses negation of a proposition: (41a) involves correction of pronunciation; (41b) expresses cancellation of a Quantity implicature; c concerns a grammatical correction; $d$ involves a correction of register. The point is that metalinguistic negation can object to any aspect of an utterance, not just the propositional

745 content.

The metalinguistic negation phenomenon is of particular interest to constructional approaches because, along with the special semantic behavior just described, it possesses special morphosyntactic properties, so that it is appropriate to speak of the metalinguistic construction. First, metalinguistic negation does not act as a negative polarity trigger, not

750 surprisingly since semantically it does not negate a proposition.

(42) a. John didn't manage to solve *any/some of the problems, he managed to solve all of them. (Horn 1985: 135)

b. I wouldn't rather walk, but I'm willing to. (Kay 2004: 688)

755

In (42a) the negative polarity item any is rejected and in (42b) the positive polarity item

${ }^{6}$ Horn cites Ducrot $(1972,1973)$, Grice $(1967 / 1989,1975)$, and Wilson (1975) as precursors. Oswald Ducrot (1972) was, to our knowledge, the first to use the term metalinguistic negation (négation métalinguistique). 
rather is welcomed.

Secondly, metalinguistic negation does not allow morphologically or lexically incorporated negation.

760 (43) a. A bad outcome *improbable/not probable; it's certain.

b. I I doubt/don't believe he'll come; I'm sure of it.

Finally, a rectification clause, which is almost always present and always understood, cannot be introduced by but.

765 (44) a. He's not happy; (*but) he's delirious.
b. Her name isn't [dzæ'kwalın];
(*but)it's [3aklin'].

The metalinguistic comparative construction was discussed briefly in section 3 , as was metalinguistic negation. Again, we see evidence of a grammatical construction, as against 770 an implicature or trope, in observing special constraints on the syntax.

(45) a. This cat is more stupid than malicious.

b. $\quad *$ This cat is stupider than malicious.

c. This cat is more stupid than he is malicious.

d. This cat's stupidity exceeds his malice.

The metalinguistic comparative in version (45a) is read as proposing that stupid is a more apt description of the cat than malicious; it does not mean the same as (45d). The metalinguistic comparative also resists morphological incorporation, as shown in (45b).

780 Example (45c), with a non-ellipted than-clause, does not yield a metalinguistic interpretation, but rather means roughly the same as (45d).

The class of metalinguistic operators includes the expressions dubbed hedges by Lakoff (1973). English hedges include the expressions strictly speaking, loosely, technically

785 (speaking), kinda (equivalently kind of, sorta, sort of). According to Kay (1984):

[a] hedged sentence, when uttered, often contains a comment on itself or on its utterance or on some part thereof. For example, when someone says, Loosely speaking France is hexagonal, part of what they have uttered is a certain kind of comment on the locution 
790 France is hexagonal. In this sort of metalinguistic comment, the words that are the subject of the comment occur both in their familiar role as part of the linguistic stream and in a theoretically unfamiliar role as part of the world the utterance is about (Kay 1984: 129).

795 That is, in saying Loosely speaking France is hexagonal one at once claims that France is hexagonal and signals that there is something 'loose' about the claim being made, or the way it's being made.

The attested sentence (46) similarly makes a claim, and the same time makes a comment on the making of that claim:

800

(46) Chomsky has a very sorta classical theory of syntax.

The adverb very intensifies the adjective classical, but the metalinguistic hedge sorta signals that the speaker is unsure that classical is the mot juste. If sorta were simply an attenuator,

805 like slightly for example, sentence (46) would mean something close to (47) but it clearly does not.

$$
\text { Chomsky has a very slightly classical theory of syntax. }
$$

810 Rather, the intensification of very is heard as part of the interpretation of (46) and sorta is heard as a comment on the aptness of the word classical as a name for the property (of Chomsky's theory of syntax) the speaker has in mind.

Kinda and sorta also have a syntax that distinguishes them from ordinary deintensifiers, like slightly. Briefly, kinda/sorta can modify any projection of any major category. Kay 815 (2004: 699) gives the following examples distinguishing the syntactic behavior of kinda/sorta from that of deintensifying adverbs. 
(48) a. a very slightly but unevenly worn tire

820

b. $\quad$ *a very sorta but surprisingly classical theory

(49) a. That tire is worn very slightly.

b. $\quad *$ That tire is worn very sorta.

(50) a. That tire is worn, but only very slightly.

825 b. *That tire is worn, but only very sorta.

(51) a. That [very slightly $]_{i}$ worn tire is proportionately $y_{i}$ discounted.

b. $\quad *$ That [very sorta $]_{i}$ classical theory is correspondingly ${ }_{i}$ admired.

9. Information flow

The central question addressed by theories of information structure is: why do grammars provide so many different ways of expressing the same proposition? The answer given is that the construction space of English and other languages is shaped by level-mapping constraints involving the three-termed relationship among syntactic roles, semantic roles and

835 pragmatic roles, in particular topic and focus (Lambrecht 1995). The examples in (52)

illustrate the range of syntactic and prosodic means available for expressing the proposition 'The dog ate the leftovers' in English (points of prosodic prominence are marked by small caps):

(52) a. The dog ate the LEFTOVERS.

840 b. The DOG ate the LEFTOVERS.

c. The LEFTOVERS, the DOG ate.

d. It's the DOG that ate the leftovers.

845 Lambrecht (1994) and Lambrecht and Michaelis (1998) propose that the prosodic and syntactic permutations in (52) amount to differences in the presuppositional content of the constructions that license them. The relevance of presupposition to the pattern in (52e) is no doubt relatively obvious: as a cleft sentence, (52d) presupposes the propositional function 'The dog ate $\mathrm{x}$ ', and the prosodic peak marks the focus, or 'new information': the identity of

850 the variable (Jackendoff 1972: chapter 6). It is less obvious how presupposition comes into play in the other sentences: (52a), for example, can but need not presuppose the 
propositional function evoked by (52d); (52a) could answer the question (53a) as readily as it could (53b):

(53) a. What did the dog do NOw?

b. What did the dog eat?

In the context of (53a), (52a) represents a predicate-focus sentence, and as such it is interpreted according to Lambrecht \& Michaelis's (1998: 498ff) Principle of Accent Projection: an accented argument expression (in this case, the leftovers) can extend its

860 semantic value to an unaccented predicate (in this case, ate), in which case the predicate and argument form a single information unit. In the case of (52a), this unit is a focal unit.

But what of (52b)? If the two peaks of (52b) were each presumed to represent foci, we could not easily explain why it, just like its single-peak analog (52a), can serve as an answer to the 'broad' question (53a). Lambrecht (1994: Chapter 4) and Lambrecht \& Michaelis

865 (1998) propose that both the single- and double-peak prosodic patterns are the products of focus constructions, which affect the presuppositional properties of predicate-argument combinations. Lambrecht (1994: chapter 5) proposes three focus constructions, which are listed and exemplified in (54), along with the communicative function associated with each pattern:

870 (54) a. Argument focus, e.g., SOCIETY's to blame. Function: identifying a variable in a presupposed open proposition.

b. $\quad$ Predicate focus, e.g., She speaks several LANGUAGES. Function: predicating a property of a given topic.

c. Sentence focus, e.g., Your SHOE's untied. Function: introducing a new discourse referent or reporting an event or state involving such a referent.

Focus constructions behave much like argument-structure constructions, in that they impose interpretive and formal constraints on predicators and their valence members. In English, such constructions assign prosodic peaks to one or more arguments and potentially 880 to the verb itself. According to Lambrecht \& Michaelis (1998), the assignment of prosodic 
peaks is constrained by general principles governing the prosodic expression of the topic and focus roles in a predication. In contrast to theories of sentence prosody based on the Nuclear Stress Rule of Chomsky \& Halle (1968) (see, e.g., Neeleman \& Reinhart 1998), the accentplacement principles proposed by Lambrecht \& Michaelis (1998) make no reference to

885 either linear order of constituents or hierarchical structure. Such accent-placement principles are analogous to case-marking principles based on semantic role ordering (rather than syntactic position), and they are equally critical to the functioning of a declarative, nonprocedural model of grammar: no movement transformations are required to model focus marking in flexible word-order languages and only one set of principles is needed for both

890 local and nonlocal argument instantiation, as in (55):

(55) a. It's called Republic PLAZA.

b. Republic PlazA it's called.

895 Both (55a) and (55b) illustrate the argument-focus pattern, whose accentual properties are described by a principle referred to by Lambrecht \& Michaelis (1998: 498) as the Discourse Function of Sentence Accents, viz., "A sentence accent indicates an instruction from the speaker to the hearer to establish a pragmatic relation between a denotatum and a proposition". Sentence (55a) has a locally instantiated second argument while (55b) is an

900 instance of focus fronting (Prince 1981), but the establishment of the focus relation relative to the open proposition 'It's called x' proceeds identically in the two cases. Similarly, predicates may fall under the pragmatic scope of their accented arguments whether they precede or follow them. The Principle of Accent Projection mentioned above accounts for the 'spreading' of an accented argument's focal value to its predicate — not only within the $905 \mathrm{VP}$, as in (52a), but also in the sentence-focus pattern exemplified in (54c), in which the accented argument precedes the verb that licenses it. In both cases, predicate and argument are integrated into a single focal unit. 
According to Accent Projection, while a focal predicate need not be accented, a focal argument is always accented. Is an accented argument necessarily a focus? The answer given

910 by this model is no: an accented argument may also be a topic. Sentence (52b), repeated below as (56), illustrates this point:

(56) The DOG ate the LEFTOVERS.

The two prosodic peaks in (56) have distinct discourse-pragmatic significances.

915 Removing the peak on leftovers changes (56) from a predicate-focus to an argument-focus sentence, but removing the peak on $d o g$ has no effect on the sentence's focus articulation: it remains a predicate-focus sentence. If the subject accent in (56) is not a focus accent, what is it? According to the principle referred to above as the Discourse Function of Sentence Accents, sentence accents establish a pragmatic relation, whether it is a focus relation or a

920 topic relation. This means that the referent of an accented argument expression can be either focal or topical. Lambrecht and Michaelis (1998: 499) use the term topic accent to refer to a sentence accent that marks a discourse-new or 'unratified' topic argument rather than a focus. In declarative sentences, a topic accent is necessarily accompanied by a focus accent elsewhere in the clause. (The one exception to this principle, discussed by Lambrecht and

925 Michaelis (1998), is found in WH-questions, in which the focal constituent, the WH-word, is typically unaccented and accents in the gapped portion of the clause represent topic accents, as in, e.g., Where did the POPE stay when he was in NEW YORK?) While that focus accent falls within the VP in subject-predicate sentences like (56), it may also fall within the gapped clause of a filler-gap construction like topicalization, as in (52c): The LEFTOVERS the DOG ate.

930 While (52c) and (56) feature identical accented words, these accents reverse their roles in (52c): the topicalized NP the leftovers bears a (contrastively interpreted) topic accent, while the subject of the gapped clause (the dog) bears a focus accent (see Prince 1981, 1986 for discussion of the presuppositional properties of topicalization). The principle that governs 
the discourse function of sentence accents treats both patterns under a single umbrella, but

935 the two patterns create a potential paradox for a movement-based account: how does the accented object NP change its pragmatic construal (from focus to topic) after its focus accent has been assigned in situ?

Let us now return to the question with which we began this section: what is presupposed by predicate-focus sentences like (56) and (52a)? Sentence (52a) is repeated below as (57):

940

The dog ate the LEFTOVERS.

The answer given by Lambrecht and Michaelis (1998) relies on the distinction between knowledge presuppositions and topicality presuppositions. Knowledge presuppositions

945 concern the assumed knowledge state of an addressee at the time of an utterance. Knowledge presuppositions correspond to those described in linguistic philosophy as the propositions evoked by factive verbs, definite descriptions, sentential subjects, aspectual verbs and argument-focus constructions of various kinds (Prince 1986). Topicality presuppositions concern the assumed statuses of referents as topics of current interest in a conversation.

950 Sentence-focus sentences like Your SHOE'S untied, My CAR broke down and Your PHONE'S ringing illustrate the difference between the two types of presupposition: while all of the foregoing sentences, by virtue of their definite subjects, could be said to trigger the existential presupposition (a knowledge presupposition), all lack the topicality presupposition: their subject-referents are not presumed to be topics of current interest in the 955 conversation. But the assumption that the subject referent is a topic (or predictable argument) in the predication is precisely what predicate-focus utterances convey. Put differently, the predicate-focus construction triggers the topicality presupposition. It does so, according to Lambrecht (1994), because of a communicative constraint originating from the Gricean lower bound on informativeness: the Principle of Separation of Reference and Role 
960 (PSRR). He describes this constraint by means of a maxim: "Do not introduce a referent and talk about it in the same clause" (p. 185). Michaelis and Francis (2007) observe the operation of this constraint in the distribution of lexical versus pronominal subject NPs in the Switchboard conversational corpus (Marcus, Santorini \& Marcinkiewicz 1993). Of approximately 31,000 subjects of declarative sentences, they find that only 9 percent are

965 lexical NPs, while 91 percent are pronouns. (By contrast, about 66 percent of the approximately 7500 objects of transitive verbs are lexical.) The subject-coding trends indicate that conversants tend to adhere to the PSRR: they do not typically predicate properties of discourse-new entities. Conversely, and as suggested by the relative frequency of lexical object-expression in the corpus, speakers tend to introduce new referents in

970 postverbal position and then resume them as pronominal subjects in subsequent predications. This strategy is exemplified in the following excerpt from the Fisher corpus of conversational speech:

(58) I have a friend of mine who used to be really involved in the beach volleyball circuit but uh he's not anymore but he still watches it. He coaches his daughter and all kinds of stuff.

At the same time, the presence of some 3,000 lexical-subject predications in the Switchboard corpus indicates that the PSRR is a violable constraint. The passage in (59), also from the Fisher corpus, exemplifies the use of a lexical subject (shown in boldface):

980 (59) [In a conversation about the Red Lobster restaurant] My friend used to work at Red Lobster actually, and she used to be so fed up with people coming in and being like oh it's mostly seafood.

Michaelis and Francis (2007) argue that the use of a lexical subject represents a short985 circuited form of referent introduction that privileges speaker-based effort conservation at the expense of hearer-based explicitness. The lexical-subject strategy subserves effort conservation because it allows the speaker to accomplish something in a single clause that otherwise requires two clauses: introduce a referent and say something about it. Michaelis 
and Francis argue that if one assumes the presuppositional analysis of predicate-focus

990 sentences described above, the lexical-subject strategy can be seen as a brand of presupposition manipulation akin to those described by Lewis's (1979) rule for accommodation of presupposition: "If at time $t$ something is said that requires presupposition $\mathrm{p}$ to be acceptable, and if $\mathrm{P}$ is not presupposed just before $\mathrm{t}$, then-ceteris paribus and within certain limits - presupposition P comes into existence at t" (Lewis 1979:

995 172). Applied to the case at hand, this means that if a speaker uses a predicate-focus predication when the topicality presupposition is not satisfied, the hearer is capable of supplying it, insofar as the associated existential presupposition is banal (Kay 1992): the speaker has a friend, sister, etc. Accommodation of the topicality presupposition is also potentially facilitated by the linguistic mark carried by most new topics: the topic-

1000 establishing accent found in double-peak sentences like (56).

Presuppositional properties of focus constructions are relevant not only for the description of prosody and conversational referring behavior, but also for the establishment of inheritance relations among pragmatically specialized constructions, as shown by Birner, Kaplan \& Ward (2007) in their recent study of the family of argument-structure

1005 constructions comprising th-clefts (e.g., That's John who wrote the book), equatives with epistemic would and a demonstrative subject (e.g., That would be John) and simple equatives with demonstrative subjects (e.g., That's John). The latter two constructions, they argue, should not be analyzed as truncated clefts (pace Hedberg 2003). Instead, as they demonstrate, all three constructions inherit formal, semantic and information-structure

1010 properties from an argument-focus construction used for equative assertions. The construction contains a copular verb, requires a demonstrative subject and presupposes an open proposition whose variable is referred to by the demonstrative subject. (The postcopular focal expression identifies this variable, as in other argument-focus 
constructions.) Thus, for example, in the sentence That will be John, the demonstrative

1015 subject refers to the variable in a presupposed open proposition (e.g., ' $\mathrm{x}$ is at the door'). They argue that the family of equative constructions exhibits functional compositionality, as state of affairs in which "the discourse-functional properties of a complex structure are determined by the functional and semantic properties of its component parts" (Birner, Kaplan \& Ward 2007: 319, fn. 1). Birner, Kaplan \& Ward's analysis is elegant and

1020 intuitively appealing, and further supports the claim that constructional and compositional modes of analysis are compatible.

\section{Conclusion}

In asking what constructions mean we must also ask how constructions mean. Constructions

1025 invoke formal properties ranging from syntactic categories to prosodic features to fixed lexical forms. All such patterns must interact in the licensing of utterances. The recursive nature of a language comes from the fact that we can use in one construction a sign that is an instance of another construction. While no current syntactic theory has failed to acknowledge that verbal idioms and their ilk can be embedded as the terminal nodes of

1030 regularly constructed phrases, non-constructionists have been less apt to acknowledge another fact about embedding: regular patterns can be embedded in idiomatic ones. Examples include the WXDY interrogative construction analyzed by Kay \& Fillmore (1999), the subjectless tag sentences analyzed by Kay (2002) and the double-copula construction analyzed by Brenier \& Michaelis (2005). We believe that the seamless

1035 integration of relatively idiomatic constructions with more productive ones in actual sentences provides an additional challenge to the notion of a privileged 'core' grammar.

\section{References}


Akmajian, Adrian 1984. Sentence types and the form-function fit. Natural Language and Linguistic Theory 2, 1-23.

Birner, Betty, Jeffrey Kaplan \& Gregory Ward 2007. Functional compositionality and the interaction of discourse constraints. Language 83, 317-343.

Borsley, Robert 2004. An Approach to English comparative correlatives. In: S. Müller (ed.). Proceedings of the fourth conference on Head-Driven Phrase Structure Grammar. Stanford: CSLI Publications, 70-92.

Brenier, Jason M. \& Laura Michaelis 2005. Optimization via syntactic amalgam: Syntaxprosody mismatch and copula doubling. Corpus Linguistics and Linguistic Theory 1, $45-88$.

Chomsky, Noam 1995. The Minimalist Program. Cambridge, MA: MIT Press.

1050 Chomsky, Noam \& Morris Halle 1968. The Sound Pattern of English. New York: Harper and Row.

Copestake, Ann, Dan Flickinger, Carl Pollard \& Ivan A. Sag 2005. Minimal recursion semantics: An introduction. Research on Language and Computation 3, 281-332.

Cornulier, Benoît de 1986. Effets de sens. Paris: Editions de Minuit.

1055 Culicover, Peter 1970. One more can of beer. Linguistic Inquiry 1, 366-369.

Culicover, Peter 1997. Syntactic Nuts: Hard Cases in Syntax. Oxford: Oxford University Press.

Culicover, Peter \& Ray S. Jackendoff 1997. Semantic subordination despite syntactic coordination. Linguistic Inquiry 28, 195-217.

1060 Culicover, Peter \& Ray Jackendoff 1999. The view from the periphery: the English comparative correlative. Linguistic Inquiry 30, 543-571. 
Dubois, John 2007. Argument structure: grammar in use. In: J. Dubois, L. Krumpf \& W. Ashby (eds.). Preferred Argument Structure: Grammar as Architecture for Function. Amsterdam: Benjamins, 11-60.

1065 Ducrot, Oswald 1972. Dire et ne pas Dire. Paris: Hermann.

Ducrot, Oswald 1973. La Preuve et le Dire. Paris: Mame.

Fillmore, Charles J. 1985. Frames and the semantics of understanding. Quaderni di Semantica 6, 222-254.

Fillmore, Charles J. 1986. Varieties of conditional sentences. In: F. Marshall, A. Miller \& Z.-S. Zhang (eds.). Proceedings of the Third Eastern States Conference on Linguistics. Columbus, Ohio: Ohio State University Department of Linguistics, 163182.

Fillmore, Charles J. 1999. Inversion and constructional inheritance. In: G. Webelhuth, J.-P. Koenig \& A. Kathol (eds.). Lexical and Constructional Aspects of Linguistic Explanation. Stanford: CSLI Publications, 113-28.

Fillmore, Charles J., Paul Kay \& Mary C. O’Connor 1988. Regularity and idiomaticity in grammatical constructions: The case of let alone. Language 64, 501-538.

Gawron, Jean Mark 1985. A parsimonious semantics for prepositions and CAUSE. In: <editors?>. Proceedings of the Twenty-First Meeting of the Chicago Linguistics Society, Part 2: Papers from the Parasession on Causatives and Agentivity. <address: publisher>, $32-47$.

Gawron, Jean Mark 1986. Situations and prepositions. Linguistics and Philosophy 9, 427476.

Ginzburg, Jonathan \& Ivan A. Sag 2000. Interrogative Investigations: The Form, Meaning and Use of English Interrogatives. Stanford: CSLI Publications. 
Goldberg, Adele 1995. Constructions: A Construction Grammar Approach to Argument Structure. Chicago: University of Chicago Press.

Goldberg, Adele 2006. Constructions at Work: The Nature of Generalizations in Language. Oxford: Oxford University Press.

1090 Grice, H. Paul 1967. Logic and conversation: The 1967 William James lectures. Harvard University, Cambridge, MA. Reprinted as Grice 1989.

Grice, H. Paul 1975. Logic and conversation. In: P. Cole \& J. L. Morgan (eds.). Syntax and Semantics, Vol. 3: Speech Acts. New York: Academic Press, 41-58.

Grice, H. Paul 1989. Studies in the Way of Words. Cambridge, MA: Harvard University 1095 Press.

Hedberg, Nancy 2000. The referential status of clefts. Language 76, 891-920.

Horn, Laurence R. 1985. Metalinguistic negation and pragmatic ambiguity. Language 61, $121-174$.

Horn, Laurence R. 1989. A Natural History of Negation. Chicago: University of Chicago 1100 Press.

Jackendoff, Ray 1972. Semantic Interpretation in Generative Grammar. Cambridge, MA: MIT Press.

Jackendoff, Ray 1990. Semantic Structures. Cambridge, MA: MIT Press.

Jackendoff, Ray 1997. The Architecture of the Language Faculty. Cambridge, MA: MIT 1105 Press.

Kay, Paul 1984. The kind of/sort of construction. Berkeley Linguistics Society 10: 128-137.

Kay, Paul 1989. Contextual operators: respective, respectively, and vice versa. In: <editor(s)>. The Proceedings of the Fifteenth Annual Meeting of the Berkeley Linguistics Society. Berkeley, CA: Berkeley Linguistics Society, Inc., 181-192. 1110 Kay, Paul 1990. Even. Linguistics and Philosophy 13, 59-111. 
Kay, Paul 1992. The inheritance of presuppositions. Linguistics and Philosophy 15, 333381.

Kay, Paul 1997. Words and the Grammar of Context. Stanford: CSLI Publications.

Kay, Paul 2002. English subjectless tagged sentences. Language 78, 453-481.

1115 Kay, Paul 2004. Pragmatic aspects of constructions. In: L. Horn \& G. Ward (eds.). The Handbook of Pragmatics. Oxford: Blackwell, 675-700.

Kay, Paul 2005. Argument-structure constructions and the argument-adjunct distinction. In:

M. Fried \& H. Boas (eds.). Grammatical Constructions: Back to the Roots.

Amsterdam: Benjamins, 71-98.

1120 Kay, Paul \& Charles J. Fillmore 1999. Grammatical constructions and linguistic generalizations: The 'what's X doing Y' construction. Language 75, 1-33.

Ladd, Robert 1995. Intonational Phonology. Cambridge: Cambridge University Press.

Lakoff, George 1973. Hedges: A study in meaning criteria and the logic of fuzzy concepts.

The Journal of Philosophical Logic 2, 458-508.

1125 Lambrecht, Knud 1987. On the status of SVO sentences in French discourse. In: R. Tomlin (ed.). Coherence and Grounding in Discourse. Amsterdam: Benjamins, 217-261.

Lambrecht, Knud 1988. There was a farmer had a dog: Syntactic amalgams revisited. In: <editor(s)>. Proceedings of the Fourteenth Annual Meeting of the Berkeley Linguistics Society. Berkeley, CA: Berkeley Linguistics Society, Inc. 319-339.

1130 Lambrecht, Knud 1990. What, me, worry? Mad magazine sentences revisited. In: <editors>. Proceedings of the Sixteenth Annual Meeting of the Berkeley Linguistics Society.

Berkeley, CA: Berkeley Linguistics Society, Inc., 215-228.

Lambrecht, Knud 1994. Information Structure and Sentence Form. Cambridge: Cambridge University Press. 
1135 Lambrecht, Knud 1995. The Pragmatics of Case: On the relationship between semantic, grammatical and pragmatic roles in English and French. In: M. Shibatani \& S. Thompson (eds.). Essays in Semantics in Honor of C.J. Fillmore. Cambridge: Cambridge University Press, 145-190.

Lambrecht, Knud \& Laura A. Michaelis 1998. Sentence accent in information questions: Default and projection. Linguistics and Philosophy 21, 477-544.

Levin, Beth \& Tova Rapoport 1988. Lexical subordination. In: <editors>. Proceedings of the Twenty-Fourth Annual Meeting of the Chicago Linguistic Society. < address: publisher>, 275-289.

Lewis, David 1979. Scorekeeping in a language game. Journal of Philosophical Logic 8, 339-359.

Makkai, Adam 1972. Idiom Structure in English. Mouton: The Hague.

Marcus, Mitchell, Beatrice Santorini \& Mary Ann Marcinkiewicz 1993. Building a large annotated corpus of English: The Penn Treebank. Computational Linguistics 19, 313 330.

1150 Michaelis, Laura 1994a. A case of constructional polysemy in Latin. Studies in Language $18,45-70$.

Michaelis, Laura 1994b. Expectation contravention and use ambiguity: The Vietnamese connective cung. Journal of Pragmatics 21, 1-36.

Michaelis, Laura 1996. On the use and meaning of already. Linguistics and Philosophy 19, $477-502$.

Michaelis, Laura 2004. Type shifting in construction grammar: An integrated approach to aspectual coercion. Cognitive Linguistics 15, 1-67.

Michaelis, Laura A. \& Knud Lambrecht 1996. Toward a construction-based model of language function: The case of nominal extraposition. Language 72, 215-247. 
1160 Michaelis, Laura \& Hartwell Francis 2007. Lexical subjects and the conflation strategy. In:

N. Hedberg \& R. Zacharski (eds.). Topics in the Grammar-Pragmatics Interface:

Papers in Honor of Jeanette K. Gundel. Amsterdam: John Benjamins, 19-48.

Neeleman, Ad \& Tanya Reinhart 1998. Scrambling and the PF-interface. In: M. Butt \& W.

Geuder (eds.). The Projection of Arguments: Lexical and Compositional Factors.

1165 Chicago: CSLI Publications, 309-353.

Nunberg, Geoffrey, Ivan Sag \& Thomas Wasow 1994. Idioms. Language 70, 491-538.

Prince, Ellen 1981. Topicalization, focus movement, and Yiddish movement: A pragmatic differentiation. In: <editors>. The Proceedings of the Seventh Annual Meeting of the Berkeley Linguistics Society. Berkeley, CA: Berkeley Linguistics Society, Inc., 249264.

Prince, Ellen 1986. On the syntactic marking of presupposed open propositions. In:

<editors>. Proceedings of the Twenty-Second Annual Meeting of the Chicago Linguistics Society. <address: publisher>, 208-222.

Sag, Ivan A. forthcoming. English filler-gap constructions. Language.

1175 Sweetser, Eve 1994. From Etymology to Pragmatics. Cambridge: Cambridge University Press.

Szabó, Zoltán 2007. Compositionality. In: E. Zalta (ed.). The Stanford Encyclopedia of Philosophy, http://plato.stanford.edu/archives/spr2007/entries/compositionality, Spring 2007.

1180 Talmy, Leonard 1985. Lexicalization patterns: Semantic structure in lexical forms. In: T. Shopen (ed.). Language Typology and Syntactic Description, Volume 3. Cambridge: Cambridge University Press, 57-149.

Wilson, Deidre 1975. Presupposition and Non-Truth-Conditional Semantics. New York: Academic Press. 
1190 Keywords: Construction Grammar, Idioms, Compositionality

Paul Kay, Berkeley, California (USA)

Laura A. Michaelis, Boulder, Colorado (USA) 